\title{
Microbiology, resistance patterns, and risk factors of mortality in ventilator-associated bacterial pneumonia in a Northern Thai tertiary-care university based general surgical intensive care unit
}

\author{
This article was published in the following Dove Press journal: \\ Infection and Drug Resistance \\ 16 August 2014 \\ Number of times this article has been viewed
}

\author{
Kaweesak Chittawatanarat \\ Wuttipong Jaipakdee \\ Narain Chotirosniramit \\ Kamtone Chandacham \\ Tidarat Jirapongcharoenlap \\ Division of Surgical Critical Care \\ and Trauma, Department of Surgery, \\ Faculty of Medicine, Chiang Mai \\ University, Chiang Mai, Thailand
}

Background: Ventilator-associated pneumonia (VAP) occurrence, causative pathogens, and resistance patterns in surgical intensive care units (SICU) are different between Western and developing Asian countries. In Thailand, resistant organisms have progressively increased in the last decade. However, the evidence describing causes of VAP and its outcomes, especially secondary to resistant pathogens, in Asian developing countries' SICUs is very limited. Therefore, the objective of this study was to describe the incidence, pathogen characteristics, and risk factors that impact mortality and patient survival following VAP in a tertiary Northern Thai SICU. Methods: Between 2008 and 2012, VAP occurred in a total of 150 patients in Chiang Mai University's general SICUs ( $6.3 \pm 2.8$ cases per 1,000 mechanical ventilator days). The following clinical data were collected from 46 patients who died and 104 patients who survived: microbiologic results, susceptible patterns, and survival status at hospital discharge. Antimicrobial susceptibility patterns were classified as susceptible, multidrug resistant (MDR), extensively drug resistant (XDR), and pan-drug resistant (PDR). The hazard ratio (HR) was calculated for risk factor analysis.

Results: Regarding the microbiology, gram negative organisms were the major pathogens $(n=142$, 94.7\%). The first three most common organisms were Acinetobacter baumannii $(38.7 \%$ of all organisms, mortality 41.4\%), Klebsiella pneumoniae (17.3\%, mortality 30.8\%), and Pseudomonas aeruginosa $(16.7 \%$, mortality $16 \%)$ respectively. The most common gram positive organism was Staphylococcus aureus (4.0\%, mortality 50\%). The median day of VAP occurrence were significantly different between the three groups $(P<0.01)$ : susceptible (day 4), MDR (day 5), and XDR (day 6.5). Only half of all VAP cases were caused by susceptible organisms. Antibiotic resistance was demonstrated by $49.3 \%$ of the gram negative organisms and $62.5 \%$ of the gram positive organisms. Extensive drug resistance was evident only in Acinetobacter baumannii (30.6\%) and Pseudomonas aeruginosa $(1.3 \%)$. No pan-drug resistance was found during surveillance. The significant HR risk factors were age $(P=0.03)$, resistant organisms $(P=0.04)$, XDR $(P=0.02)$, and acute physiology and chronic health evaluation II score $(<0.01)$. Acinetobacter baumannii $(P=0.06)$ and intubation due to severe sepsis $(P=0.08)$ demonstrated a trend toward a significant increase in the HR. On the other hand, there were significantly decreased HRs in trauma patients $(P=0.01)$. Initial administration of appropriate antibiotic therapy had a tendency toward a significant decrease in the HR $(P=0.08)$.

Conclusion: Gram negative organisms were the primary cause of bacterial VAP in Chiang Mai University's general SICU. Resistant strains were present in half of all VAP cases and were associated with the day of VAP onset. Regarding risk factors, age, acute physiology, chronic health evaluation II score, resistant organisms (especially XDR), and being a non-trauma patient increased the risk of mortality. Keywords: surgical intensive care unit, ventilator-associated pneumonia, device-related incidence rate, drug resistant organism, Acinetobacter baumannii
Correspondence: Kaweesak

Chittawatanarat

Trauma, Department of Surgery, Faculty of Medicine, Chiang Mai University, Maharaj Nakorn Chiang Mai Hospital, Intawarorod Rd, Sripume District, Muang, Chiang Mai, 50200, Thailand

Tel +6653945533

Fax +66 53946139

Email kchittaw@gmail.com (c) (i) (3) 2014 Chittawatanarat et al. This work is published by Dove Medical Press Limited, and licensed under Creative Commons Attribution - Non Commercial (unported, v3.0)
License. The full terms of the License are available at http://creativecommons.org/licenses/by-nc/3.0/. Non-commercial uses of the work are permitted without any further permission from Dove Medical Press Limited, provided the work is properly attributed. Permissions beyond the scope of the License are administered by Dove Medical Press Limited. Information on how to request permission may be found at: http://www.dovepress.com/permissions.php 


\section{Introduction}

The mechanical ventilator (MV) provides the most common organ support in an intensive care unit (ICU). The prevalence of patients requiring a MV in a Thai surgical ICU (SICU) survey was found to be $56.0 \%{ }^{1}$ One of the most common complications whilst on a MV was ventilator-associated pneumonia (VAP), creating a burden in overall health care costs. ${ }^{2}$ The incidence and mortality rates of VAP vary due to several factors such as the study population, time of onset, causative organisms, and appropriate antibiotic therapy. ${ }^{3}$ There were differences in the incidence of causative VAP organisms between Western and Asian developing countries. ${ }^{4,5}$ In most Western hospital SICUs, gram positive organisms, especially methicillin-resistant Staphylococcus aureus (MRSA), are the prominent pathogens. ${ }^{6-8}$ This is in contrast to most of Asian developing countries where the most common pathogens were gram negative organisms and evidence also showed an increase in drug resistant strains. ${ }^{5,9}$ However, there are few existing reports on these pathogens' characteristics in the context of SICUs in Asian developing countries. Therefore, the objective of this study was to describe the incidence, pathogen characteristics, and risk factors which impact mortality and survival in patients who developed VAP in our SICU.

\section{Material and methods}

The authors collected 5 years of prospective surveillance data from the SICU and sub-SICU in a 1,400 bed universitybased hospital in the Northern region of Thailand. There were 21 adult SICU beds and sub-SICU beds in the division of surgical critical care and trauma. These ICUs accommodate vascular, trauma, thoracic, and abdominal surgical patients. Surveillance data were retrieved from the hospital infectious control (IC) data registry. IC working groups were comprised of multi-departmental coordinator physicians, IC nurses (ICN), and IC ward coordinator nurses (ICWs). In SICU, seven ICWs followed and inspected all nosocomial infection (NI) occurrences based on standard international criteria. The IC coordinator of critical care surgeons confirmed all new NI cases. The hospital IC regularly collected all cases of NI and reported them monthly to an IC committee.

\section{Diagnosis of VAP}

VAP diagnosis was defined as pneumonia occurring more than 48 hours after patients had been intubated and received mechanical ventilation, as well as using American Thoracic Society criteria which is comprised of three groups of criteria as clinical, radiographic, and microbiological criteria. ${ }^{3,10}$
The criteria included a new and persistent infiltration present for more than 48 hours on a chest radiograph, plus two or more of the following: 1) fever of more than $38^{\circ} \mathrm{C}$ or less than $36^{\circ} \mathrm{C} ; 2$ ) leukocytosis of more than 10,000 or leucopenia of less than 5,000 cells $/ \mathrm{mL}$; 3) purulent tracheobronchial secretion; and 4) gas exchange degradation. Positive microbiological culture confirmation was also required. All of our culture specimens were collected by endotracheal aspiration. All sputum cultures of the specimens were interpreted by the surgical critical care attending physician based on definition criteria. ${ }^{11}$ Patients with only initial clinical suspicion and negative culture result were excluded from surveillance. Late onset of VAP was defined as VAP occurring more than 4 days ( $>96$ hours) after intubation. ${ }^{12}$

\section{Definition of resistance and appropriate antibiotic therapy}

Definition of resistance in this study was based on the criteria specified by European Center for Disease Prevention and Control and the Center for Disease Control and Prevention (CDC). ${ }^{13}$ Multidrug resistant (MDR) was defined as resistance to at least one agent in three or more antimicrobial categories. Extensively drug resistant (XDR) was defined as resistance to at least one agent in all but two or fewer antimicrobial categories. Pan-drug resistant (PDR) was defined as resistance to all agents in all antimicrobial categories. ${ }^{13} \mathrm{In}$ addition, extended spectrum beta lactamases (ESBLs) were gram negative bacteria which were non-susceptible to first-, second-, and third-generation cephalosporins and monobactams but are not affected by cephamycins or carbapenem antimicrobial agents. ${ }^{14}$ MRSA is the strain of Staphylococcus aureus resistant to methicillin and other more common antibiotics such as oxacillin, penicillin, and amoxicillin. ${ }^{15}$ ESBLs and MRSA were classified as MDR in this study. The in vitro antibiotic susceptibility was determined by the antibiotic disc diffusion test. Dilution test using Minimal Inhibitory Concentration (MIC) was not performed in this study. Patients receiving appropriate antibiotic therapy were defined as receiving empirical antimicrobial agent(s) which the organism was sensitive to, within 24 hours of the time of VAP diagnosis, before reporting of the culture result.

\section{Study design and statistical analysis}

This study was a retrospective analysis of all patients who developed VAP, reported to the IC surveillance system, between 1 January 2008 and 31 December 2012. The Faculty of Medicine, Chiang Mai University Ethics Committee approved this study. The authors collected sex, 
age, comorbidities, acute physiologic assessment, and chronic health evaluation II score (acute physiology and chronic health evaluation [APACHE] II score), type of surgical diseases and procedures, reason for endotracheal intubation, organisms of VAP, antibiotic susceptibility, appropriate antibiotic, lengths of ICU and hospital stays. Patient status of death and survival was recorded at hospital discharge. We reported data as percentages for categorical data, mean with standard deviation (SD) for normal distribution variables and median with interquartile range (IQR) for nonparametric distribution variables. Data were analyzed by STATA software (version 11.0; StataCorp LP, College Station, TX, USA). Group differences of two samples were tested using the chi-squared test for categorized variables, Student's $t$-test and Mann-Whitney $U$ test for continuous variables with parametric and non-parametric distribution respectively. Cox regression analysis was performed for time to event analysis and reported with hazard ratio (HR) with $95 \%$ confidence interval (CI).

\section{Results}

During a 5 year period, a total of 23,546 mechanical ventilator days (MVD) (4,709 $\pm 266.4 \mathrm{MVD} /$ year) were observed in the general SICU and sub-SICU. The surveillance center collected a total of 150 VAP patients during this period. The average VAP incidence density rate during this period was $6.3 \pm 2.8$ cases per 1,000 MVD. The median of VAP onset occurred on day 5 after intubation (IQR day 3-8). Fortysix patients $(30.7 \%)$ died in hospital after VAP diagnosis (Table 1). The patients who did not survive were significantly older than the patients who survived (mean \pm SD: $59.5 \pm 19.0$ years and $49.4 \pm 20.7$ years; $P<0.01$ ). The overall median ICU and hospital length of stay in days (IQR) was 19.0 (13-34) and 26.0 (16-43) respectively. However, there were no differences between the length of stay between the mortality group and the survival group. The top three comorbidities of VAP patients were cardiovascular disease, diabetes, and hypertension respectively. Nearly two thirds (62.7\%) of VAP occurred in trauma patients. Trauma patients had a significantly lower mortality rate than non-trauma patients (trauma versus non-trauma $20.2 \%$ versus $48.2 \%$; $P<0.001$ ). The top four major reasons for intubation were as follows: an alteration of consciousness $(60.58 \%)$, postoperatively $(22.0 \%)$, severe sepsis $(8.7 \%)$, and hypovolemic shock (8.7\%). The major locations of the first intubation occurred in the referring hospital (44.67\%), operating room $(24.0 \%)$, and ICU $(15.33 \%)$. Regarding the onset of VAP, onset after intubation, and susceptibility patterns, the median of the onset day (IQR) was significantly different among the VAP organisms
Table I Characteristics of patients with VAP in an SICU

\begin{tabular}{|c|c|c|c|c|}
\hline $\begin{array}{l}\text { Patient } \\
\text { characteristics }\end{array}$ & $\begin{array}{l}\text { All } \\
(n=150)\end{array}$ & $\begin{array}{l}\text { Death } \\
(n=46)\end{array}$ & $\begin{array}{l}\text { Survived } \\
(n=104)\end{array}$ & $P$-value \\
\hline Male (\%) & $106(70.7)$ & $31(67.4)$ & $75(72.1)$ & 0.56 \\
\hline Age in years (SD) & $52.6(20.7)$ & $59.6(19.0)$ & $49.5(20.8)$ & $<0.01$ \\
\hline $\begin{array}{l}\text { APACHE II score } \\
\text { (SD) }\end{array}$ & $19.7(4.0)$ & $21.6(4.0)$ & $18.7(3.8)$ & $<0.01$ \\
\hline $\begin{array}{l}\text { ICU LOS in days, } \\
\text { median (IQR) }\end{array}$ & $\begin{array}{l}19.0 \\
(13-34)\end{array}$ & $\begin{array}{l}24.5 \\
(11-39)\end{array}$ & $\begin{array}{l}17.0 \\
(13-28.5)\end{array}$ & 0.21 \\
\hline $\begin{array}{l}\text { Hospital LOS in } \\
\text { days, median (IQR) }\end{array}$ & $\begin{array}{l}26.0 \\
(16-43)\end{array}$ & $\begin{array}{l}26.0 \\
(13-42)\end{array}$ & $\begin{array}{l}26.0 \\
(16-43.5)\end{array}$ & 0.44 \\
\hline \multicolumn{5}{|c|}{ Type of patients, $\mathbf{n}(\%)$} \\
\hline Non-trauma & $56(37.3)$ & $27(58.7)$ & $29(27.9)$ & $<0.01$ \\
\hline General & 31 (20.7) & $18(39.1)$ & $13(12.5)$ & \\
\hline Vascular & $18(12.0)$ & $6(13.0)$ & $12(11.5)$ & \\
\hline $\begin{array}{l}\text { Thoracic } \\
\text { (non-cardiac) }\end{array}$ & $7(4.7)$ & $3(6.5)$ & $4(3.9)$ & \\
\hline Trauma & $94(62.7)$ & $19(4 \mid .3)$ & $75(72.1)$ & \\
\hline Neurosurgical & $73(48.7)$ & II (23.9) & $62(59.6)$ & \\
\hline $\begin{array}{l}\text { Non- } \\
\text { neurosurgical }\end{array}$ & $21(14.0)$ & $8(17.4)$ & $13(12.5)$ & \\
\hline \multicolumn{5}{|c|}{ Comorbidities, n (\%) } \\
\hline Diabetics & $13(8.7)$ & $6(13.0)$ & $7(6.7)$ & 0.22 \\
\hline Hypertension & $9(6.0)$ & $4(8.7)$ & $5(4.8)$ & \\
\hline Cardiovascular & $16(10.7)$ & $4(8.7)$ & $12(11.5)$ & \\
\hline $\begin{array}{l}\text { Chronic lung } \\
\text { disease }\end{array}$ & $8(5.3)$ & $5(10.9)$ & $3(2.9)$ & \\
\hline Cirrhosis & $4(2.7)$ & $3(6.5)$ & $\mathrm{I}(\mathrm{I} .0)$ & \\
\hline Others & $6(4.0)$ & $2(4.3)$ & $4(3.8)$ & \\
\hline \multicolumn{5}{|c|}{ Cause of intubation, $\mathbf{n}(\%)$} \\
\hline Postoperative & $33(22.0)$ & II (23.9) & $22(2 \mid .2)$ & $<0.01$ \\
\hline $\begin{array}{l}\text { Alteration of } \\
\text { consciousness }\end{array}$ & $73(48.7)$ & $10(21.7)$ & $63(60.6)$ & \\
\hline Severe sepsis & $13(8.7)$ & $8(17.4)$ & $5(4.8)$ & \\
\hline Hypovolemic shock & $13(8.7)$ & $6(13.1)$ & $7(6.7)$ & \\
\hline Pulmonary edema & $5(3.3)$ & $3(6.5)$ & $2(1.9)$ & \\
\hline Others & $13(8.7)$ & $8(17.4)$ & $5(4.8)$ & \\
\hline
\end{tabular}

Abbreviations: APACHE, Acute Physiology of Chronic and Health Evaluation; ICU, intensive care unit; LOS, length of stay; SD, standard deviation; IQR, interquartile range; VAP, ventilator-associated pneumonia; $\mathrm{SICU}$, surgical intensive care unit.

(susceptible versus MDR versus XDR: 4 days (3-6) versus 5 days (3-8) versus 6.5 days $(4-12) ; P<0.01)$.

Regarding the microbiology, gram negative bacteria were the major pathogens (94.7\%) and gram positive organisms were only $5.3 \%$. There were no fungal infections reported during this study. Of these gram negative bacteria, the first three most common organisms were Acinetobacter baumannii (38.7\% of all VAP/mortality $41.4 \%$ ), Klebsiella pneumoniae (17.3\%/mortality $30.8 \%$ ) and Pseudomonas aeruginosa (16.7\%/mortality $16 \%$ ). The most common gram positive organism was Staphylococcus aureus (4.0\%/mortality 50\%). Regarding the drug sensitivity pattern, the numbers in the antibiotic sensitive group and the drug resistance (DR) group were equal (50\% in each group). Figure 1 demonstrates the 


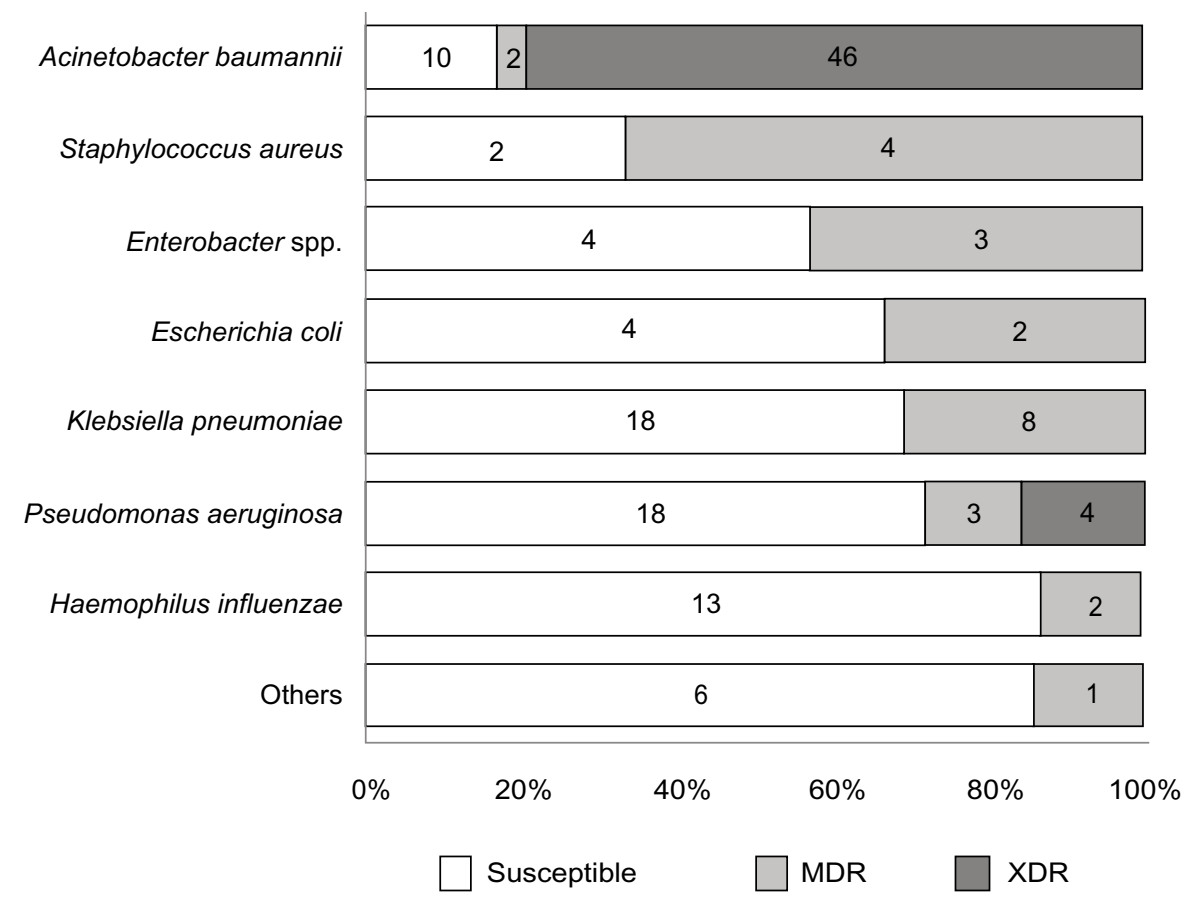

Figure I Percentage of drug susceptibility patterns for each organism.

Notes: Numbers represent the number of patients; susceptible means susceptible to all antimicrobial agents in 6 patients infected with Stenotrophomonas spp. (2), Proteus mirabilis (I); Streptococcus pneumonia (I); Citrobaacter koseri (I) and Pasteurella spp. (I); and multidrug resistant in I patient infected with Enterococcus spp (I).

Abbreviations: MDR, multidrug resistant; XDR, extensively drug resistant.

proportion of drug susceptibility of each organism. Proteus mirabilis, Stenotrophomonas spp. Streptococcus pneumoniae, Citrobacter koseri and, Pasteurella spp. were non-MDR organisms. The remaining pathogens had varying levels of drug resistance for each pathogen (Acinetobacter baumannii [82.8\%], Enterobacter spp. [42.9\%], Escherichia coli [33.3\%], Klebsiella pneumonia [30.8\%], Pseudomonas aeruginosa [28\%], Haemophilus influenza [13.3\%], Staphylococcus aureus [66.7\%], and Enterococcus faecium [100\%]; Figure 1). Only one VAP patient was infected by a drug resistant strain of Enterococcus faecium. Overall the mortality of the DR group was significantly higher than the sensitivity group $(41.3 \%$ resistant group versus $20.0 \%$ susceptible group; $P<0.01$ ). XDR gram negative bacteria occurred in one third of the total VAP patients and also showed a significantly higher rate of mortality than the sensitivity group $(P<0.01)$. Acinetobacter baumannii (46/50 [92\%]) and Pseudomonas aeruginosa (4/50 [8\%]) were the only two gram negative XDR organisms. There were no XDR gram positive bacteria (Table 2). No mortality was reported in patients who were infected with Haemophilus influenza and Pasteurella spp. There was no resistance in our specimens in the following cases: bacteriogram, colistin for gram negative bacteria, and vancomycin for gram positive bacteria. Bacteriogram sensitivity between $50 \%-60 \%$ were carbapenem (imipenem-cilastatin acid [60.8\%], meropenem
[60.9\%]), cefoperazone-sulbactam (60.5\%), piperacillintazobactam (58.1\%), and levofloxacin (52.6\%) and less than $50 \%$ were cefotaxime (41.6\%), ciprofloxacin (49.6\%), and amoxicillin-clavulanic acid (28.1\%). Both clindamycin and oxacillin had bacteriogram activity in only one third of the gram positive bacteria cases.

For the risk factor analysis in Table 3, the significantly increased HR parameters were age (HR 1.02; $P=0.03$ ), resistant organisms (HR 1.93, $P=0.04$ ), XDR (HR 2.22; $P=0.02$ ), and APACHE II score (HR 113; $P<0.01$ ). Acinetobacter baumannii (HR 1.76; $P=0.06$ ) and intubation due to severe sepsis (HR 2.00; $P=0.08)$ trended toward a significant increase of HR. In contrast, trauma patients (HR $0.47 ; P=0.01$ ) and the initial administration of appropriate antibiotic therapy (HR $0.59 ; P=0.08$ ) had a significantly and trend decreased HR respectively. Figure 2 demonstrates the survival time of patients with some risk factors including drug susceptibility pattern (sensitive versus MDR versus XDR), type of surgical patients (trauma versus non-trauma), administration of appropriate antibiotic (appropriate versus inappropriate), and organism type (Acinetobacter baumannii versus others).

\section{Discussion}

Different studies reported varied VAP incidence rates ranging from $5 \%$ to $67 \%$, which may be confounded by the 
Table 2 Organism involved in VAP in an SICU

\begin{tabular}{|c|c|c|c|c|}
\hline & $\begin{array}{l}\text { All } \\
(n=150)\end{array}$ & $\begin{array}{l}\text { Death } \\
(n=46)\end{array}$ & $\begin{array}{l}\text { Survived } \\
(n=104)\end{array}$ & $P$-value \\
\hline \multicolumn{5}{|l|}{ Organism types, n (\%) } \\
\hline Gram negative & $142(94.7)$ & $43(93.48)$ & $99(95.2)$ & 0.67 \\
\hline Gram positive & $8(5.3)$ & $3(6.5)$ & $5(4.8)$ & \\
\hline \multicolumn{5}{|c|}{ Gram negative organisms } \\
\hline $\begin{array}{l}\text { Acinetobacter } \\
\text { baumannii }\end{array}$ & $58(38.7)$ & $24(52.2)$ & $34(32.7)$ & $<0.01$ \\
\hline Klebsiella pneumoniae & $26(17.3)$ & $8(I 7.4)$ & $18(17.3)$ & \\
\hline \multicolumn{5}{|l|}{ aeruginosa } \\
\hline Haemophilus influenzae & $15(10.0)$ & $0(0)$ & $15(14.4)$ & \\
\hline Enterobacter spp. & $7(4.7)$ & $2(4.3)$ & $5(4.8)$ & \\
\hline Escherichia coli & $6(4.0)$ & I (2.I) & $5(4.8)$ & \\
\hline Stenotrophomonas spp. & $2(1.3)$ & $2(4.3)$ & $0(0)$ & \\
\hline Citrobacter koseri & $\mathrm{I}(0.7)$ & $\mathrm{I}(2.2)$ & $0(0)$ & \\
\hline Pasteurella spp. & $\mathrm{I}(0.7)$ & $0(0)$ & I (I.0) & \\
\hline Proteus mirabilis & $\mathrm{I}(0.7)$ & I $(2.2)$ & $0(0)$ & \\
\hline \multicolumn{5}{|c|}{ Gram positive organisms } \\
\hline Staphylococcus aureus & $6(4.0)$ & $3(6.5)$ & $3(2.9)$ & 0.45 \\
\hline Enterococcus faecium & I (0.7) & $0(0)$ & I (I.0) & \\
\hline $\begin{array}{l}\text { Streptococcus } \\
\text { pneumoniae }\end{array}$ & I $(0.7)$ & $0(0)$ & I (I.0) & \\
\hline \multicolumn{5}{|c|}{ Antibiotic susceptibility, n (\%) } \\
\hline \multicolumn{5}{|c|}{ Susceptibility pattern } \\
\hline Susceptible organisms & $75(50.0)$ & $15(32.6)$ & $60(57.7)$ & $<0.01$ \\
\hline Resistant organisms & $75(50.0)$ & $31(67.4)$ & $44(42.3)$ & \\
\hline \multicolumn{5}{|l|}{ Appropriate antibiotics } \\
\hline Inappropriate & $61(40.7)$ & $26(56.5)$ & $35(33.6)$ & $<0.01$ \\
\hline Appropriate & $89(59.3)$ & $20(43.5)$ & $69(66.4)$ & \\
\hline Gram negative & $142(94.7)$ & $43(93.5)$ & $99(95.2)$ & 0.02 \\
\hline Susceptible organisms & $72(48.0)$ & $14(30.4)$ & $58(55.8)$ & \\
\hline MDR organisms & $20(13.3)$ & $6(13.0)$ & $14(13.5)$ & \\
\hline XDR organisms & $50(33.3)$ & $23(50.0)$ & $27(26.0)$ & \\
\hline Gram positive & $8(5.3)$ & $3(6.5)$ & $5(4.8)$ & 0.64 \\
\hline Susceptible organisms & $3(2.0)$ & $\mathrm{I}(2.2)$ & $2(1.9)$ & \\
\hline MDR organisms & $5(2.7)$ & $2(4.3)$ & $3(2.8)$ & \\
\hline \multicolumn{5}{|c|}{ Implementation of VAP prevention, $\mathbf{n}(\%)$} \\
\hline Before (2008-2010) & $103(68.7)$ & $28(60.9)$ & $75(72.1)$ & 0.17 \\
\hline After (20II-20I2) & $47(31.3)$ & $18(39.1)$ & $29(27.9)$ & \\
\hline
\end{tabular}

Abbreviations: MDR, multidrug resistant; XDR, extensively drug resistant; VAP, ventilator-associated pneumonia; SICU, surgical intensive care unit.

presence of mixed populations with variable age groups, underlying conditions, other associated risk factors, and using different gold standards for diagnosis..$^{16}$ The National Nosocomial Infections Surveillance System of the CDC reported the median rate of VAP cases per 1,000 MVD in the US was higher in SICUs (range 6.2-11.4) than in medical ICUs (3.7). ${ }^{17}$ In Asian countries, the incidence density of VAP varied between 3.5-9.0 cases per 1,000 MVD. ${ }^{5}$ The incidence of VAP over a 5 year period of surveillance in our SICU was comparable with rates reported by the CDC and the Asian reports (6.3 \pm 2.8 cases per 1,000 MVD). Trauma patients had a higher occurrence of VAP than non-trauma
Table 3 Hazard ratio of mortality following VAP

\begin{tabular}{|c|c|c|}
\hline & $\begin{array}{l}\text { Hazard ratio } \\
\text { (95\% confidence } \\
\text { interval) }\end{array}$ & $P$-value \\
\hline Male & $0.93(0.50-1.72)$ & 0.81 \\
\hline Age & $1.02(1.00-1.03)$ & 0.03 \\
\hline Initial APACHE II score & $1.13(1.05-1.23)$ & $<0.01$ \\
\hline Late onset & $1.43(0.79-2.60)$ & 0.24 \\
\hline Resistant organisms & $1.93(1.04-3.59)$ & 0.04 \\
\hline MDR & $1.39(0.59-3.31)$ & 0.45 \\
\hline XDR & $2.22(1.16-4.27)$ & 0.02 \\
\hline Appropriate antibiotic & $0.59(0.33-1.06)$ & 0.08 \\
\hline Gram negative & $0.88(0.27-2.85)$ & 0.83 \\
\hline Acinetobacter baumannii & $1.76(0.98-3.13)$ & 0.06 \\
\hline Klebsiella pneumoniae & $1.09(0.5 \mathrm{I}-2.35)$ & 0.82 \\
\hline Pseudomonas aeruginosa & $0.42(0.15-1.18)$ & 0.10 \\
\hline Escherichia coli & $0.58(0.08-4.22)$ & 0.59 \\
\hline Enterobacter spp. & $0.86(0.21-3.58)$ & 0.84 \\
\hline Staphylococcus aureus & $1.63(0.50-5.29)$ & 0.41 \\
\hline Trauma & $0.47(0.26-0.85)$ & 0.01 \\
\hline Diabetic & $1.43(0.60-3.37)$ & 0.42 \\
\hline Cardiovascular & $0.91(0.42-1.95)$ & 0.80 \\
\hline Intubation due to severe sepsis & $2.00(0.93-4.33)$ & 0.08 \\
\hline Intubation due to hypovolemic shock & $1.68(0.7 \mathrm{I}-3.96)$ & 0.24 \\
\hline Postoperative intubation & $0.81(0.4 I-1.60)$ & 0.54 \\
\hline \multicolumn{3}{|l|}{ Implementation of VAP prevention } \\
\hline Susceptible organisms & $1.21(0.38-3.84)$ & 0.74 \\
\hline MDR & I.5I (0.28-8.25) & 0.64 \\
\hline XDR & $1.83(0.80-4.18)$ & 0.15 \\
\hline
\end{tabular}

Abbreviations: APACHE, Acute Physiology of Chronic and Health Evaluation; MDR, multidrug resistant; XDR, extensively drug resistant; VAP, ventilatorassociated pneumonia.

patients (trauma versus non-trauma: $62.7 \%$ versus $38.3 \%$ ). This finding was in keeping with the higher incidence rate in trauma patients reported by the CDC. ${ }^{17}$

The most common bacterial pathogen causing ventilatorassociated bacterial pneumonia in a Western surveillance program was Staphylococcus aureus with an incidence varying from $30 \%-45 \%$, of which MRSA accounts for $20 \%-40 \% .{ }^{4}$ In most Asian countries, MRSA infection was less than $20 \%{ }^{5}$ However, in Thailand, our results found MRSA incidence was less than $10 \% .{ }^{5,18} \mathrm{~A}$ recent study showed that in the VAP incidence of mixed medical-SICUs in Thailand, gram negative bacteria were the most common organisms particularly Acinetobacter baumannii (25\%-50\%), Pseudomonas aeruginosa (18\%-35\%), and Klebsiella pneumoniae (7\%-25\%), which were comparable with our results in SICU. ${ }^{5,18,19}$ In the authors' opinion, these phenomena might be explained by environmental climate, eg, gram negative organisms, especially Acinetobacter baumannii, could more rapidly colonize in a warm and humid environment found in tropical regions. In addition, transient bacteremia from skin flora, induced by invasive monitoring, might be an 
A

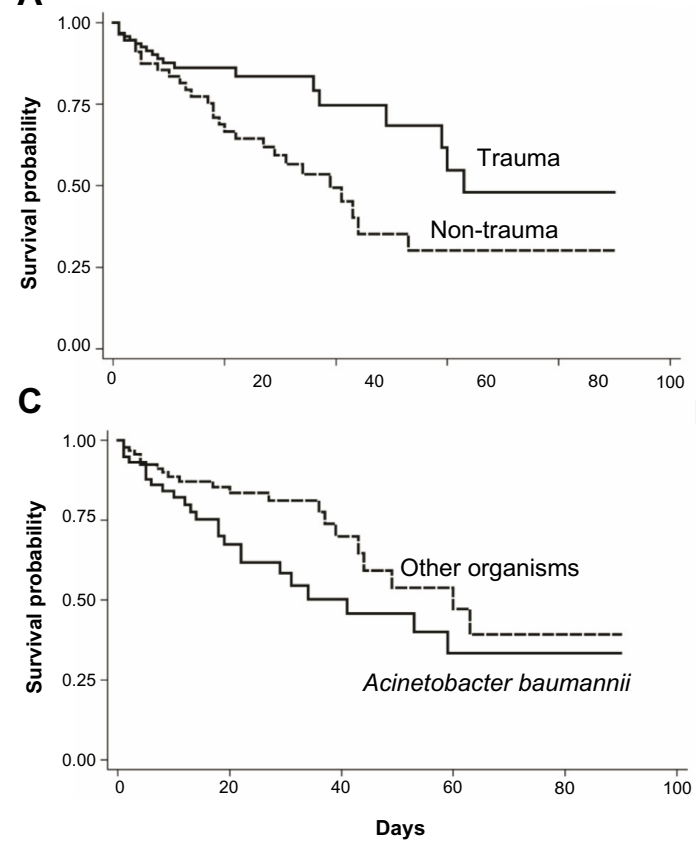

B

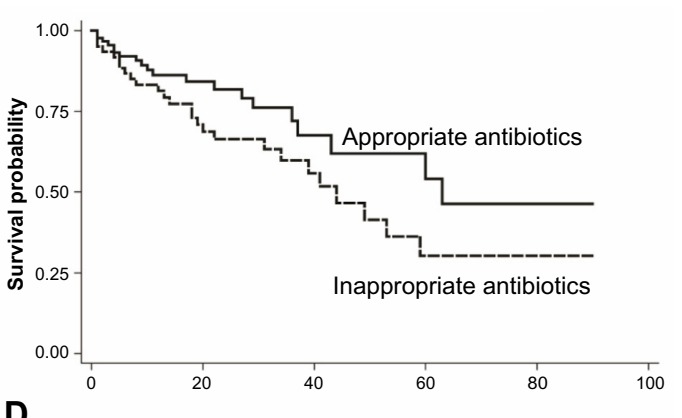

D

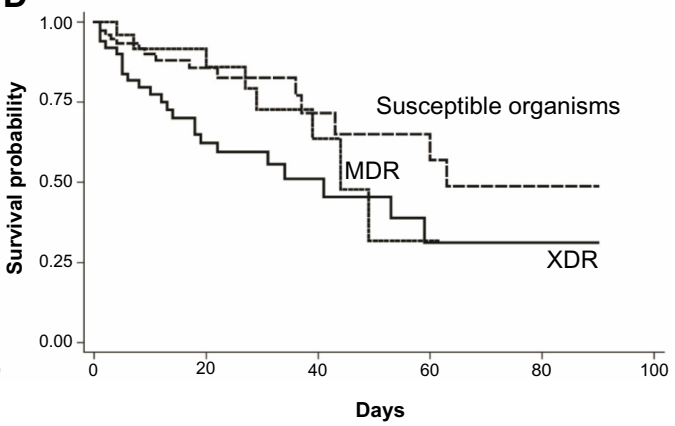

Figure 2 Kaplan-Meier survival estimation of mortality in VAP patients.

Notes: (A) Trauma patients, (B) appropriate antibiotics, (C) Acinetobacter baumannii, and (D) susceptible patterns of organisms.

Abbreviations: VAP, ventilator-associated pneumonia; MDR, multidrug resistant; XDR, extensively drug resistant.

explanatory factor. Although there were no data on the number and duration of arterial or central venous line insertions in this study, the possible higher number of these line insertions for any purposes of invasive monitoring in Western countries might be a mediating factor for higher incidence of gram positive infection of VAP in developed countries. Interestingly, the drug resistant gram negative Pseudomonas aeruginosa was also commonly cited in Western reports. ${ }^{20}$ However, the frequency of the occurrence of this organism was less than Acinetobacter baumannii in Asian countries including Thailand. ${ }^{5,18,19}$ XDR strains or Carbapenem resistant Acinetobacter baumannii have progressively increased in the last decade. ${ }^{9,21}$ This tendency corresponded to our results that more than $80 \%$ of these organisms were resistant to the usual gram negative antimicrobial agents and more than $90 \%$ of these were XDR. A stratification scoring system for guiding antibiotic therapy might increase appropriate empirical therapy. ${ }^{2}$ However, the antimicrobial drug of choice might be different based on local epidemiological data. In addition, although the burden of Staphylococcus aureus VAP in this study was small, the mortality rate was also high in this study. The early detection and appropriate antimicrobial therapy should be initiated and managed as soon as possible.

The mortality rate in our SICU was $30.6 \%$ and significantly lower in trauma patients (trauma versus non-trauma: 20.2\% versus $48.2 \%$ ). Recent meta-analysis reported the same finding but showed a lower mortality rate than our data (trauma versus non-trauma: $13.3 \%$ versus $33.2 \%$ ). ${ }^{22} \mathrm{APACHE}$ II scores and patient age were the important independent risk factors for VAP mortality in previous reports. ${ }^{22,23}$ However, the significant effect of Acinetobacter baumannii was small and demonstrated a tendency of increasing risk; the obvious results require a larger sample size of infected patients. On the other hand, resistant bacteria significantly increased mortality in a previous report. ${ }^{20}$ In addition, appropriate antibiotic therapy could significantly decrease mortality in both first and recurrent episodes. ${ }^{24,25}$ Most cases of inappropriate antibiotic therapy occurred in XDR patients. Therefore, suspected XDR infection should be treated with empiric broad spectrum antibiotics based on local guidance. The VAP onset was one of the independent factors of XDR and this might be a concerning factor for selection and initiating broad spectrum antimicrobial agents. ${ }^{2,26}$ The authors suggest that mortality may be decreased by choosing appropriate antibiotic therapy for drug resistant bacteria based on the time of VAP onset and gram strain identification. The occurrence of gram positive VAP organisms was low. The effect on mortality was high but it was not statistically significant. The reason behind this was a small sample size, which resulted in less valid results.

The strength of this study was the 5 year surveillance data which sub-classified the drug resistance and demonstrated the effects on mortality in SICU. This report 
was the first analysis of the impact of VAP in a Thai SICU. However, there were some inevitable limitations. Firstly, the incidence of VAP varied because preventive VAP bundle strategies (bed elevation of more than 30 degrees, using weaning of MV protocol, ensuring appropriate cuff pressure measurement, chlorhexidine oral rinse, sedation holiday, and early ambulation) were implemented during the last 2 years of surveillance. Although VAP occurrence decreased from 34.3 to 23.5 cases per year (Table 2 ), there was no significant difference on HR of mortality between before and after preventive VAP bundle strategies implementation (Table 3). Secondly, the surveillance data reported only the major pathogen on the culture report according to the attending physician's opinion. Therefore, we did not report poly-microbial VAP incidence. However, the epidemiology and outcomes of patients did not differ regarding mono- or poly-microbial VAP. ${ }^{27}$ Finally, because of limited resources, all of the microscopic culture specimens were collected from endotracheal sputum aspiration. These might be discordant if compared to using more accurate bronchoscopic alveolar lavage. However, the accordance results between endotracheal sputum aspiration and bronchoscopic alveolar lavage results of previous reports in trauma patients between these two methods were $83 \%$ for gram strain and $73 \%$ for culture reports. ${ }^{28}$

\section{Conclusion}

Gram negative organisms were the major cause of bacterial VAP in Chiang Mai University's general SICUs. Resistant strains are present in half of all VAP cases and were associated with its onset. Regarding risk factors, age, APACHE II score, resistant organisms (especially XDR) and being a non-trauma patient increased the risk of mortality.

\section{Author contributions}

K Chittawatanarat and W Jaipakdee drafted the manuscript, participated in the study design, and performed the statistical analysis. N Chotirosniramit, K Chandacham, and $\mathrm{T}$ Jirapongcharoenlap participated in co-ordination and prospective data collection. All authors contributed toward data analysis, drafting, and revising the manuscript.

\section{Acknowledgments}

The authors would like to thank the Infection Control Unit of the Faculty of Medicine, Chiang Mai University Hospital. We give our grateful thanks to all of the infection control nurses in the SICU for their assistance in providing the surveillance data.

\section{Disclosure}

The authors have no conflicts of interest to declare.

\section{References}

1. Chittawatanarat K, Jaikriengkrai K, Permpikul C, Thai Society of Critical Care Study group. Survey of respiratory support for intensive care patients in 10 Tertiary hospital of Thailand. J Med Assoc Thai. 2014;97(Suppl 1):S8-S14.

2. Wilke M, Grube R. Update on management options in the treatment of nosocomial and ventilator assisted pneumonia: review of actual guidelines and economic aspects of therapy. Infect Drug Resist. 2013;7:1-7.

3. American Thoracic Society. Guidelines for the management of adults with hospital-acquired, ventilator-associated, and healthcare-associated pneumonia. Am J Respir Crit Care Med. 2005;171(4):388-416.

4. Jones RN. Microbial etiologies of hospital-acquired bacterial pneumonia and ventilator-associated bacterial pneumonia. Clin Infect Dis. 2010;51(Suppl 1):S81-S87.

5. Chawla R. Epidemiology, etiology, and diagnosis of hospital-acquired pneumonia and ventilator-associated pneumonia in Asian countries. Am J Infect Control. 2008;36(Suppl 4):S93-S100.

6. Minei JP, Nathens AB, West M, et al. Inflammation and the Host Response to Injury, a Large-Scale Collaborative Project: patient-oriented research core - standard operating procedures for clinical care. II. Guidelines for prevention, diagnosis and treatment of ventilator-associated pneumonia (VAP) in the trauma patient. JTrauma. 2006;60(5):1106-1113.

7. Zygun DA, Zuege DJ, Boiteau PJ, et al. Ventilator-associated pneumonia in severe traumatic brain injury. Neurocrit Care. 2006;5(2):108-114.

8. Hamilton LA, Christopher Wood G, Magnotti LJ, et al. Treatment of methicillin-resistant Staphylococcus aureus ventilator-associated pneumonia with high-dose vancomycin or linezolid. J Trauma Acute Care Surg. 2012;72(6):1478-1483.

9. Apisarnthanarak A, Buppunharun W, Tiengrim S, Sawanpanyalert P, Aswapokee N. An overview of antimicrobial susceptibility patterns for gram-negative bacteria from the National Antimicrobial Resistance Surveillance Thailand (NARST) program from 2000 to 2005. J Med Assoc Thai. 2009;92(Suppl 4):S91-S94.

10. Koenig SM, Truwit JD. Ventilator-associated pneumonia: diagnosis, treatment, and prevention. Clin Microbiol Rev. 2006;19(4):637-657.

11. Morris AJ, Tanner DC, Reller LB. Rejection criteria for endotracheal aspirates from adults. J Clin Microbiol. 1993;31(5):1027-1029.

12. Kollef MH, Silver P, Murphy DM, Trovillion E. The effect of lateonset ventilator-associated pneumonia in determining patient mortality. Chest. 1995;108(6):1655-1662.

13. Magiorakos AP, Srinivasan A, Carey RB, et al. Multidrug-resistant, extensively drug-resistant and pandrug-resistant bacteria: an international expert proposal for interim standard definitions for acquired resistance. Clin Microbiol Infect. 2012;18(3):268-281.

14. Paterson DL, Bonomo RA. Extended-spectrum beta-lactamases: a clinical update. Clin Microbiol Rev. 2005;18(4):657-686.

15. Gorwitz RJ, Kruszon-Moran D, McAllister SK, et al. Changes in the prevalence of nasal colonization with Staphylococcus aureus in the United States, 2001-2004. J Infect Dis. 2008;197(9):1226-1234.

16. McCrory R, Jones DS, Adair CG, Gorman SP. Pharmaceutical strategies to prevent ventilator-associated pneumonia. $J$ Pharm Pharmacol. 2003;55(4):411-428.

17. National Nosocomial Infections Surveillance System. National Nosocomial Infections Surveillance (NNIS) System Report, data summary from Jan 1992 through Jun 2004, issued Oct 2004 Am J Infect Control. 2004;32(8):470-485.

18. Reechaipichitkul W, Phondongnok S, Bourpoern J, Chaimanee P. Causative agents and resistance among hospital-acquired and ventilator-associated pneumonia patients at Srinagarind Hospital, northeastern Thailand. Southeast Asian J Trop Med Public Health. 2013;44(3):490-502. 
19. Werarak P, Kiratisin P, Thamlikitkul V. Hospital-acquired pneumonia and ventilator-associated pneumonia in adults at Siriraj Hospital: etiology, clinical outcomes, and impact of antimicrobial resistance. J Med Assoc Thai. 2010;93(Suppl 1):S126-S138.

20. Parker CM, Kutsogiannis J, Muscedere J, et al. Ventilator-associated pneumonia caused by multidrug-resistant organisms or Pseudomonas aeruginosa: prevalence, incidence, risk factors, and outcomes. J Crit Care. 2008;23(1):18-26.

21. Garnacho-Montero J, Amaya-Villar R. Multiresistant Acinetobacter baumannii infections: epidemiology and management. Curr Opin Infect Dis. 2010;23(4):332-339.

22. Melsen WG, Rovers MM, Groenwold RH, et al. Attributable mortality of ventilator-associated pneumonia: a meta-analysis of individual patient data from randomised prevention studies. Lancet Infect Dis. 2013;13(8):665-671.

23. Celis R, Torres A, Gatell JM, Almela M, Rodriguez-Roisin R, Agusti-Vidal A. Nosocomial pneumonia. A multivariate analysis of risk and prognosis. Chest. 1988;93(2):318-324.
24. Dupont H, Mentec H, Sollet JP, Bleichner G. Impact of appropriateness of initial antibiotic therapy on the outcome of ventilator-associated pneumonia. Intensive Care Med. 2001;27(2):355-362.

25. Mueller EW, Hanes SD, Croce MA, Wood GC, Boucher BA, Fabian TC. Effect from multiple episodes of inadequate empiric antibiotic therapy for ventilator-associated pneumonia on morbidity and mortality among critically ill trauma patients. J Trauma. 2005;58(1):94-101.

26. Caricato A, Montini L, Bello G, et al. Risk factors and outcome of Acinetobacter baumanii infection in severe trauma patients. Intensive Care Med. 2009;35(11):1964-1969.

27. Combes A, Figliolini C, Trouillet JL, et al. Incidence and outcome of polymicrobial ventilator-associated pneumonia. Chest. 2002;121(5): 1618-1623.

28. Michetti CP, Aldaghlas T. Differences in management and mortality with a bronchoalveolar lavage-based diagnostic protocol for ventilator-associated pneumonia. J Trauma Acute Care Surg. 2012; 72(1):242-246.
Infection and Drug Resistance

\section{Publish your work in this journal}

Infection and Drug Resistance is an international, peer-reviewed openaccess journal that focuses on the optimal treatment of infection (bacterial, fungal and viral) and the development and institution of preventive strategies to minimize the development and spread of resistance. The journal is specifically concerned with the epidemiology of antibiotic

\section{Dovepress}

resistance and the mechanisms of resistance development and diffusion in both hospitals and the community. The manuscript management system is completely online and includes a very quick and fair peerreview system, which is all easy to use. Visit http://www.dovepress.com/ testimonials.php to read real quotes from published authors. 